\title{
Combining cell sorting with gas chromatography to determine phytoplankton group-specific intracellular dimethylsulphoniopropionate
}

\author{
Stephen D. Archer*, Glen A. Tarran, John A. Stephens, Lindsay J. Butcher, \\ Susan A. Kimmance
}

Plymouth Marine Laboratory, Prospect Place, Plymouth PL1 3DH, UK

\begin{abstract}
An approach combining flow-cytometric fluorescence-activated cell sorting (FACS) of specific phytoplankton groups and subsequent quantification of dimethylsulphoniopropionate (DMSP) content by gas chromatography (GC) is introduced and applied to cultivated microalgae and natural seawater samples. The FACS-GC based method produces statistically robust estimates of the intracellular DMSP content of a variety of phytoplankton groups ranging from prokaryotic Synechococcus spp. to eukaryotic nanophytoplankton. Comparison between FACS and traditional filtration approaches to determine intracellular DMSP content of cultivated microalgae illustrates variable responses between species to the 2 methods. Natural photosynthetic nanoeukaryote populations contained high intracellular DMSP content; comparable to many cultivated prymnesiophyte taxa. A surprisingly high DMSP content was found in natural populations of Synechococcus spp., in contrast to previous values measured in cultivated strains, but possibly confirming the uptake and retention of DMSP by this photosynthetic prokaryote. When combined, the DMSP contributions of each phytoplankton group amounted to between 40 and $57 \%$ of total DMSP in each water sample, with the bulk of the total comprising nanoeukaryote-DMSP. The approach has high potential to provide information that enables better parameterisation of phytoplankton functional types in mechanistic dimethyl sulphide models and to help elucidate the environmental controls that govern the extent and diversity of DMSP production in the oceans.
\end{abstract}

KEY WORDS: Phytoplankton · Dimethylsulphoniopropionate $\cdot$ DMSP $\cdot$ Dimethyl sulphide $\cdot$ DMS · Flow cytometry $\cdot$ Cell sorting

\section{INTRODUCTION}

Dimethylsulphoniopropionate (DMSP) is the principal precursor of the trace gas dimethyl sulphide (DMS), and is synthesised by a small number of flowering plants, macroalgae and a variety of microalgae, including oceanic phytoplankton (Challenger \& Simpson 1948, Gage et al. 1997). Understanding what controls DMSP production in the oceans is important because emissions of DMS contribute to the nucleation and growth of aerosol particles, enhancing formation of cloud condensation nuclei $(\mathrm{CCN})$ in the marine boundary layer and potentially affecting Earth's albedo and climate (Shaw 1983, Charlson et al. 1987). Additionally, DMS may influence atmospheric chemistry through reactions with the photolysis products of biogenic halocarbons, and pre-existing sea-salt and organic aerosol particles (Vogt et al. 1996, von Glasow \& Crutzen 2004, Leck \& Bigg 2005). In addition to being the major precursor to DMS, DMSP can also be a significant component of primary production, and a vehicle for the transport of significant levels of carbon and sulphur through foodwebs (Kiene et al. 2000, Archer et al. 2001, Simó et al. 2002). Concentrations of 
DMSP and DMS are dynamically linked in the surface ocean through a complex network of physicochemical and biological processes (Kiene et al. 2000). Understanding which of these processes govern the concentrations of DMSP and DMS requires informed parameterisation of mechanistic models, from which the key processes can potentially be incorporated into climate models.

Process-based, prognostic models of DMS concentrations are generally highly sensitive to parameters that directly or indirectly prescribe the DMSP content of phytoplankton functional types (PFTs) (Archer et al. 2004, Six \& Maier-Reimer 2006, Vogt et al. 2010). Whether explicitly or implicitly parameterised, modelled intracellular DMSP concentrations are often based on measurements from phytoplankton in laboratory culture, with values for each modelled PFT derived from averages of a number of species or strains of variable representation in the natural community (Archer et al. 2004, Six \& Maier-Reimer 2006, Vogt et al. 2010).

There is limited information on the intracellular DMSP content of specific taxa or on PFTs in natural phytoplankton communities. This is in part due to the practical difficulties of physically separating PFTs in natural populations. As a consequence, attempts to partition the DMSP pool amongst PFTs have taken a variety of approaches. Correlations between the abundance of specific taxa or types and DMSP concentrations can reveal the potentially important contributors to DMSP standing stocks and provide the basis for estimates of their intracellular DMSP content, albeit with high levels of uncertainty (Turner et al. 1988, Malin et al. 1993, Matrai \& Keller 1993). Size fractionation by filtration has demonstrated that the majority of DMSP (on average $65 \%$ of the total) in open seas or oceans is contained in particles of 0.7 to $10 \mu \mathrm{m}$ (Belviso et al. 1993, Belviso et al. 2001); with the $<1$ to $2 \mu \mathrm{m}$ size range making up 2 to $25 \%$ of the DMSP pool (Corn et al. 1996). High proportions of DMSP in larger size fractions have been associated with specific dinoflagellate species (Belviso et al. 2000, Jean et al. 2005). Chemotaxonomic pigments have also been used to identify the principal taxonomic groups that contribute to DMSP production. Significant correlations between the 0.7 to $10 \mu \mathrm{m}$ size fraction of DMSP and total concentrations of 19'-hexanoyloxyfucoxanthin and 19'butanoyloxyfucoxanthin illustrate the importance of nanoplanktonic prymnesiophyte and chrysophyte species to the DMSP pool in the open ocean (Belviso et al. 2001). However, none of these approaches provide direct estimates of the intracellular DMSP content of specific taxa or PFTs and, therefore, provide limited information on which to base model parameterisation or elucidate the factors that drive DMSP production.
We present a novel approach to determine the intracellular DMSP content of specific groups of phytoplankton in natural waters. The approach combines flow cytometric discrimination of phytoplankton groups, flow cytometric sorting of those groups and sensitive quantification of their DMSP concentrations. Flow cytometry is now a standard tool for the enumeration and characterisation of phytoplankton of $<20 \mu \mathrm{m}$. Characterisation of particles based on cell dimensions, morphology and autofluorescence of photosynthetic pigments provides rapid discrimination and enumeration of natural phytoplankton populations to varying levels of taxonomic distinction (Yentsch et al. 1983, Archer et al. 2001, Tarran et al. 2001). Several flow cytometric sorting mechanisms have been developed that allow high-speed physical separation of particles with a high degree of specificity and very efficient levels of recovery. The study aimed to test the approach by quantifying intracellular DMSP content in laboratory cultures of phytoplankton and in specific groups in natural phytoplankton populations in coastal and open ocean environments. The purpose of the present study is to illustrate the high potential this approach has for determining variations in the contribution of specific phytoplankton groups to the total DMSP pool, exploring environmental factors that affect intracellular DMSP content and better informing the parameterisation of mechanistic DMS models.

\section{MATERIALS AND METHODS}

An approach combining fluorescence-activated cell sorting (FACS) of phytoplankton by flow cytometry with purge-and-trap gas chromatographic (GC) analysis of DMSP concentrations was tested using both laboratory cultures of phytoplankton and natural coastal and oceanic waters. This study combines the results of research carried out at different times and places: (1) at Plymouth Marine Laboratory in 2002; (2) in the western English Channel in 2007 and 2008; and (3) in the eastern Atlantic in 2009. Two different flow sorting devices were employed to isolate distinct phytoplankton groups commonly distinguishable by flow cytometry in natural waters: a piezoelectrically driven fluid switching, mechanical mechanism and a high-speed droplet sorting system. Preliminary experiments were carried out to test the mechanical sorting approach on laboratory cultures known to vary in intracellular DMSP content and to compare this to a more established filtration approach.

Laboratory cultures. Cultures of Emiliania huxleyi CCAP 920/3 (Prymnesiophyceae), Isochrysis galbana CCAP 927/1 (Prymnesiophyceae) and Dunaliella tertiolecta CCAP 19/6B (Chlorophyceae) were used for lab- 
oratory experiments. All phytoplankton species were grown in filtered, autoclaved seawater enriched with f/2 nutrients (Guillard \& Ryther 1962), under continuous light at approximately $100 \mu \mathrm{mol}$ photons $\mathrm{m}^{-2} \mathrm{~s}^{-1}$ and at $15^{\circ} \mathrm{C}$. Cells were maintained in near-exponential growth by regular transfer to fresh medium.

Natural water samples and cell concentration. Samples used for mechanical cell sorting were collected from the Mauritanian Upwelling in the eastern Atlantic Ocean during the SOLAS-ICON cruise aboard RRS 'Discovery' (cruise D338) on 14 and 19 May 2009 (Table 1). Samples were collected using a rosette of $24 \times 201$ Ocean Test Equipment water bottles mounted on a Sea-Bird 911plus CTD profiler. Mechanical sorting was carried out on board, as described below.

For tests involving droplet sorting, water was collected aboard RV 'Plymouth Quest' from the Western Channel Observatory Stns L4 and E1 on 6 June 2007 and 27 August 2008 (Table 1). In order to obtain sufficiently large volumes, seawater was obtained from a pumped supply and stored in a 201 polypropylene carboy (Nalgene, Nalge Company) during transport back to Plymouth Marine Laboratory. Although cell disruption by pumped seawater systems may occur, no loss of cell numbers in specific phytoplankton groups was observed between the pumped seawater samples and samples collected in 51 Niskin bottles at the same time and depth.

To enable sufficient cells to be sorted to provide adequate DMSP concentrations, natural samples from both the eastern Atlantic Ocean and western English Channel were pre-filtered through $200 \mu \mathrm{m}$ mesh and then concentrated by gravity filtration through a $0.22 \mu \mathrm{m}$ cartridge filter (Supor membrane, AcroPak 1000, Pall Corporation). This produced approximately a 150-fold concentration of cells in approximately $125 \mathrm{ml}$ of seawater retained in the filter capsule. The concentrating process took approximately $40 \mathrm{~min}$. Unconcentrated water from each sample was analysed by flow cytometry to determine the natural abundance of the specific groups that were sorted. The filtrate from each concentration step was used as sheath fluid for the flow cytometer during the sorting processes.
Piezoelectrically driven fluid switching (mechanical) cell sorting. Flow cytometric mechanical sorting and analysis of laboratory cultures and natural plankton populations was conducted using a FACSort flow cytometer (BD Biosciences) equipped with a blue (488 nm) argon ion laser (Spectra Physics) and running BD CellQuest ${ }^{\mathrm{TM}}$ software version 3.3. Bivariate plots of cellular light scatter (side scatter) versus red fluorescence (>650 nm), and red fluorescence versus orange fluorescence (575 $\pm 13 \mathrm{~nm}$ bandpass filter), were used to discriminate and count Synechococcus cyanobacteria, picoeukaryote phytoplankton, cryptophytes and other nanoeukaryote phytoplankton (Fig. 1).

Fluorescent beads and cells were sorted in single cell mode. Sorting performance was verified by sorting a mixture of $3.6 \mu \mathrm{m}$ diameter Flowset ${ }^{\mathrm{TM}}$ microspheres (Beckman Coulter) and $10 \mu \mathrm{m}$ diameter Immunocheck $^{\mathrm{TM}}$ microspheres (Beckman Coulter). Sort purity and recovery of beads of different size and fluorescence were verified by reanalysis of sorted samples on the flow cytometer. The same checks were also carried out with phytoplankton populations and confirmed $100 \%$ purity and $\geq 95 \%$ recovery in sorted samples.

For the laboratory cultures, it was possible due to the high abundance of cells to mechanically sort 2.5, 5.0 and $10 \times 10^{3}$ cells directly into $20 \mathrm{ml}$ vials. Sorted volumes were made up to $20 \mathrm{ml}$ with Milli-Q water and the addition of $1 \mathrm{ml}$ of $10 \mathrm{~mol} \mathrm{l}^{-1} \mathrm{NaOH}$. For the natural populations, 4 to 5 proportional numbers of cells were sorted for each phytoplankton group depending on their expected DMSP content (e.g. 2, 4, 6, 8 and $10 \times$ $10^{3}$ cells for the nanoeukaryote population, and 50, $100,150,200$ and $250 \times 10^{3}$ cells for Synechococcus spp.). For natural phytoplankton, sorted cells were collected on a filter following mechanical sorting. This was necessary due to the greater volume of sorted fluid produced during the longer sort times that were required for the comparatively dilute cell populations found in the open ocean. The flow rate of the sorted fluid stream was approximately $4.3 \mathrm{ml} \mathrm{min}^{-1}$. The fluid stream containing sorted cells was dripped into a $15 \mathrm{ml}$ glass filter funnel (Millipore) containing a $25 \mathrm{~mm}$ glass

Table 1. Details of the water samples used for FACS-GC based determination of intracellular DMSP content in natural phytoplankton communities

\begin{tabular}{|c|c|c|c|c|c|c|}
\hline Date & Location & $\begin{array}{l}\text { Water depth } \\
\text { (m) }\end{array}$ & $\begin{array}{l}\text { Sample depth } \\
(\mathrm{m})\end{array}$ & $\begin{array}{l}\text { Water temp. } \\
\qquad\left({ }^{\circ} \mathrm{C}\right)\end{array}$ & $\begin{array}{l}\text { Chlorophyll a } \\
\left(\mu \mathrm{g} \mathrm{l}^{-1}\right)\end{array}$ & $\begin{array}{c}\text { Total DMSP }( \pm \mathrm{SD}) \\
\left(\mathrm{nmol} \mathrm{l}^{-1}\right)\end{array}$ \\
\hline \multicolumn{7}{|c|}{ Mechanical sorting: eastern Atlantic } \\
\hline 14 May 2009 & $19^{\circ} 52^{\prime} \mathrm{N}, 18^{\circ} 9^{\prime} \mathrm{W}$ & 2232 & 7 & 18.4 & 0.9 & $68.7 \pm 3.0$ \\
\hline 19 May 2009 & $19^{\circ} 43^{\prime} \mathrm{N}, 18^{\circ} 6^{\prime} \mathrm{W}$ & 2734 & 8 & 18.3 & 1.5 & $69.7 \pm 2.5$ \\
\hline \multicolumn{7}{|c|}{ Droplet sorting: western English Channel } \\
\hline 6 June 2007 & $50^{\circ} 2^{\prime} \mathrm{N}, 4^{\circ} 22^{\prime} \mathrm{W}$ & 60 & 1 & 14.0 & 1.4 & $28.1 \pm 2.1$ \\
\hline 27 August 2008 & $50^{\circ} 15^{\prime} \mathrm{N}, 4^{\circ} 13^{\prime} \mathrm{W}$ & 50 & 1 & 15.6 & 10.4 & $25.3 \pm 2.5$ \\
\hline
\end{tabular}


microfiber filter (Advantec GF75, Toyo Roshi Kaisha). To avoid cell disruption and loss of intracellular DMSP, a gentle vacuum $(<2 \mathrm{~mm} \mathrm{Hg})$ was applied to maintain a minimum of $2 \mathrm{ml}$ of fluid in the filter tower during the sorting run. On completion of each sorting run the sorting fluid stream was maintained for a further $10 \mathrm{~s}$ to flush the line of any remaining cells. Drying of the filters was minimised and filters placed into $8 \mathrm{ml}$ glass vials containing $35 \mu \mathrm{l} 50 \%$ sulphuric acid and $7 \mathrm{ml}$ Milli-Q water in order to preserve the DMSP. Vials were stored at room temperature until processed for DMSP analysis.
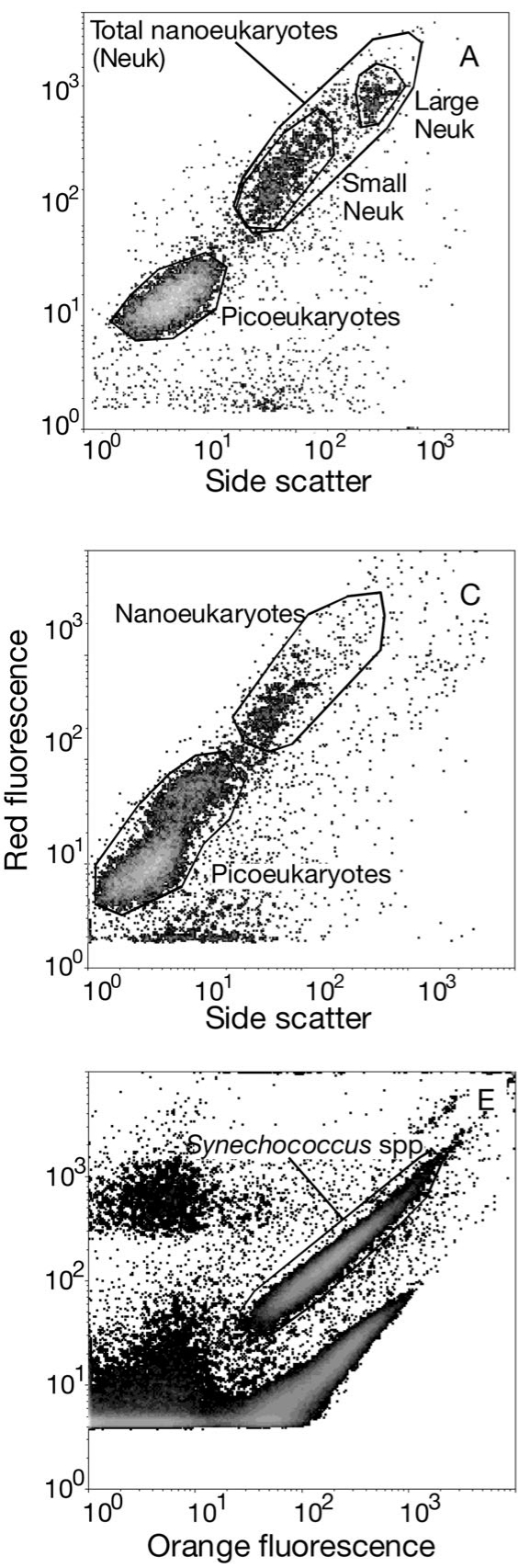

Comparison between mechanical sorting and filtration of laboratory cultures. In parallel to the mechanical sorting of laboratory cultures, aliquots of each culture corresponding to $2.5,5.0$ and $10 \times 10^{3}$ cells were gravity filtered onto $25 \mathrm{~mm}$ glass microfiber filters (Advantec GF75, Toyo Roshi Kaisha) and rinsed with $2 \mathrm{ml}$ of sterile $\mathrm{f} / 2$ media. Filters were transferred to gas-tight glass vials containing $20 \mathrm{ml}$ of $1 \mathrm{~mol} \mathrm{l}^{-1} \mathrm{NaOH}$ in Milli-Q water and identical methods were used to determine the DMSP content of vials containing either mechanically sorted cells or filtered samples (see below).
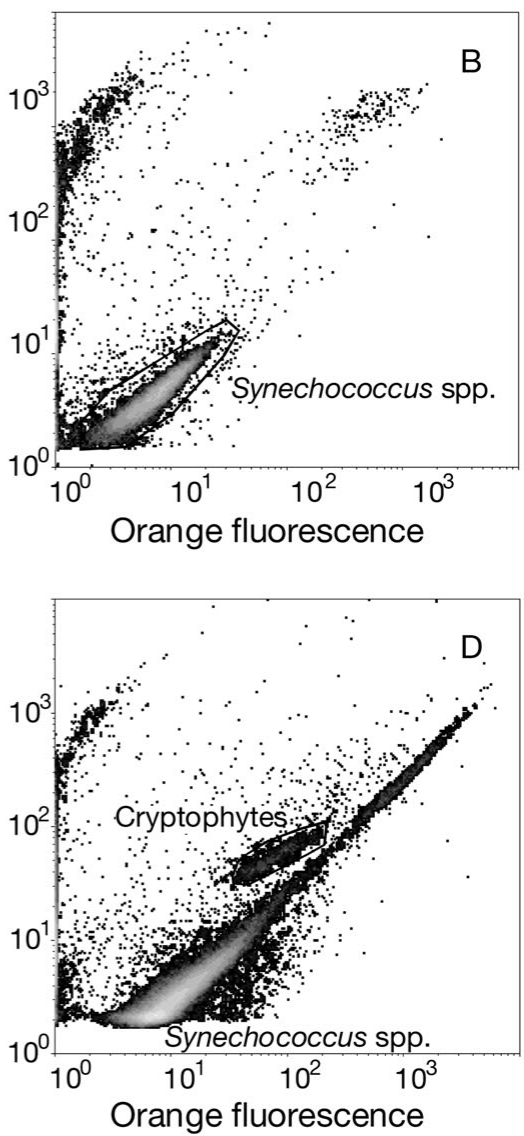

Fig. 1. Flow cytograms of the natural water samples analysed in $(A, B)$ the western English Channel and $(C, D, E)$ the eastern Atlantic. The FACS gates for the specific phytoplankton groups for which DMSP content was measured are shown in each case. (E) In the eastern Atlantic, Synechococcus spp. were sorted using different instrument settings, compared to the remaining groups 
Droplet cell sorting. Flow cytometric droplet sorting and analysis of natural coastal plankton populations was carried out using a FACSAria flow cytometer (BD Biosciences) equipped with a blue $(488 \mathrm{~nm})$ solid state laser (Coherent ${ }^{\circledR}$ Sapphire $^{\mathrm{TM}}$ ) and running BD FACSDiva software v4.1. Bivariate plots of cellular light scatter (side scatter) and red fluorescence $(695 \pm 20 \mathrm{~nm})$ and red fluorescence versus orange fluorescence (576 \pm $13 \mathrm{~nm}$ ) were used to visualise and count Synechococcus spp. cyanobacteria, picoeukaryote phytoplankton and nanoeukaryote phytoplankton (Fig. 1). The FACSAria was operated using a $100 \mu \mathrm{m}$ nozzle, with a drop-drive frequency of $30000 \mathrm{~Hz}$. BD FACS ${ }^{\mathrm{TM}}$ Accudrop beads and the FACSDiva software were used to determine the drop delay. Sort purity and recovery were checked using the approach described for the mechanical sorting method. Synechococcus spp. and picoeukaryote cells were sorted simultaneously and nanoeukaryotes were sorted alone in single cell mode (yield mask $=0$, purity mask $=32$, phase mask $=16$ ), with the sweet spot on. Where possible, 3 different numbers of cells were sorted in duplicate for each phytoplankton group. The droplet stream containing the sorted cells was collected in $8 \mathrm{ml}$ glass vials containing $5 \mu \mathrm{l}$ of $50 \% \mathrm{H}_{2} \mathrm{SO}_{4}$, to preserve the DMSP. Sorted samples were stored at room temperature until processed for DMSP analysis.

Analysis of DMSP concentrations. Total DMSP in seawater samples, dissolved DMSP $\left(\mathrm{DMSP}_{\mathrm{d}}\right)$ concentrations in the filtrate used as sheath fluid and DMSP concentrations in FACS samples were measured as DMS following alkaline hydrolysis. DMS concentrations were quantified using a purge system and cryogenic trap linked to a Varian 3800 gas chromatograph equipped with a pulsed flame photometric detector (PFPD). The DMSP in mechanically sorted samples collected on filters and preserved in $7 \mathrm{ml}$ of acidified Milli-Q water was hydrolysed to DMS by the addition of $1 \mathrm{ml}$ of $10 \mathrm{~mol} \mathrm{l}^{-1} \mathrm{NaOH}$. The smaller volumes created by the droplet sorting approach were made up to $2 \mathrm{ml}$ with Milli-Q water and hydrolysed by the addition of $0.25 \mathrm{ml}$ of $10 \mathrm{~mol} \mathrm{l}^{-1} \mathrm{NaOH}$.

Total DMSP concentrations were determined from $3 \mathrm{ml}$ whole water samples, preserved with $15 \mu \mathrm{l}$ of $50 \%$ $\mathrm{H}_{2} \mathrm{SO}_{4}$ and subsequently hydrolysed with $0.5 \mathrm{ml}$ of $10 \mathrm{~mol} \mathrm{l}^{-1} \mathrm{NaOH}, 1 \mathrm{ml}$ of which was analysed. $\mathrm{DMSP}_{\mathrm{d}}$ concentrations in the sheath fluid were determined in $3 \mathrm{ml}$ samples, preserved and hydrolysed as for total DMSP, except that the whole sample was analysed. Samples were purged with $100 \mathrm{ml} \mathrm{min}^{-1}$ helium for $5 \mathrm{~min}$ and the DMS trapped in liquid nitrogen. When triplicate experimental samples were used to test for analytical error the coefficient of variation was typically $<5 \%$ for DMSP analysis. DMS standards for calibration were prepared from DMSP (>98\% purity, Center for Analysis Spectroscopy and Synthesis, University of Groningen) in a $1.0 \mathrm{~mol} \mathrm{l}^{-1} \mathrm{NaOH}$ solution in Milli-Q water.

\section{RESULTS}

\section{Mechanical sorting of laboratory cultures}

Significant relationships between number of cells mechanically sorted and DMSP concentration were observed for Emiliania huxleyi CCAP 920/3, Isochrysis galbana CCAP 927/1 and Dunaliella tertiolecta CCAP 19/6B (Fig. 2A). The slope of the linear regression between cell number and DMSP concentration provides an estimate of the intracellular DMSP content of each species, with E. huxleyi containing more than double the DMSP content of I. galbana, and a very low but significant DMSP content in $D$. tertiolecta (Table 2). The intercept value for $D$. tertiolecta was not significantly different from zero, confirming a lack of DMS or DMSP in the sorting fluid stream, which consisted primarily of the Milli-Q water of the sheath fluid. The slightly higher values for I. galbana of $242 \pm$ 228 pg DMSP and E. huxleyi of $279 \pm 111$ pg DMSP

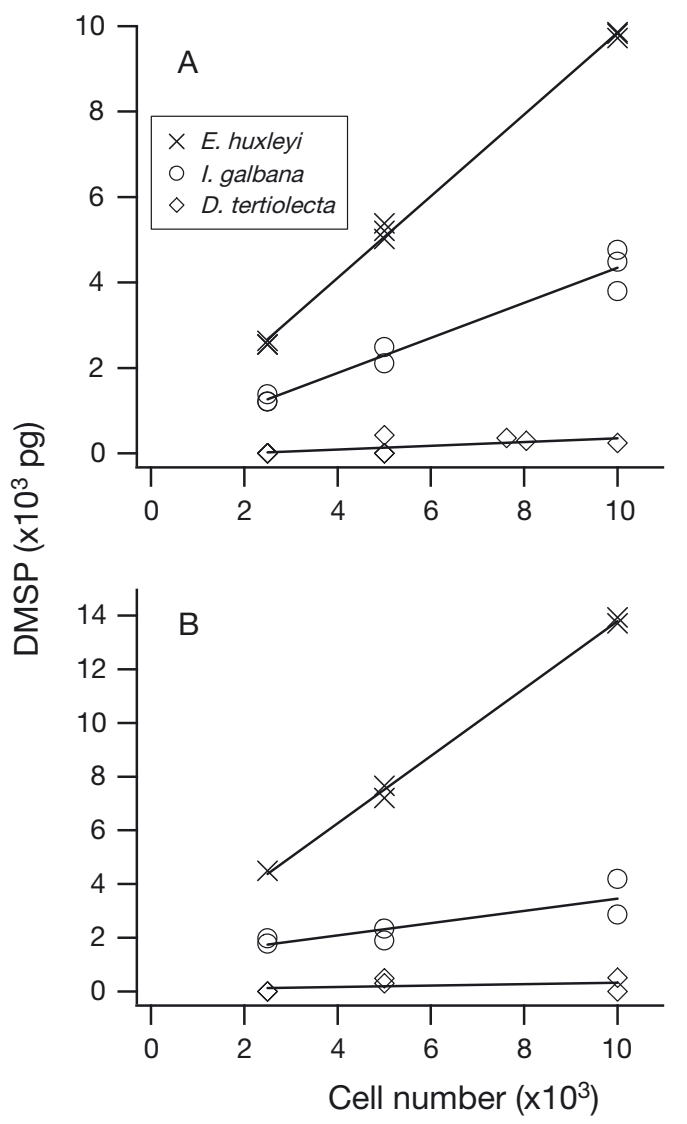

Fig. 2. Emiliania huxleyi, Isochrysis galbana and Dunaliella tertiolecta. DMSP cell content in laboratory cultures determined by (A) mechanical FACS-GC and (B) filtration. Details of the least squares, linear regression analysis of number of cells sampled versus DMSP concentration are given in Table 2 
(Table 2) suggest that a minor fraction of the measured DMSP may have been dissolved DMS or DMSP present in the original culture and included in the sorted material as part of the sorting fluid stream.

\section{Comparison between mechanical sorting and filtration of laboratory cultures}

By filtering volumes of culture containing the same numbers of cells as were mechanically sorted, a comparable estimate of intracellular DMSP content can be obtained from the relationship between number of cells filtered and DMSP concentration retained by the filter. This approach generated significant relationships between cell number and DMSP concentration for Emiliania huxleyi CCAP 920/3, Isochrysis galbana CCAP 927/1 but not for Dunaliella tertiolecta CCAP 19/6B (Fig. 2B, Table 2). Estimates of the intracellular DMSP content in E. huxleyi were significantly ( $\mathrm{p}<0.0001, F$-test of regression coefficients) higher using the filtration approach than those determined from the cell-sorting approach. In contrast, the filtration approach generated lower but not significantly different $(\mathrm{p}>$ 0.05) estimates of intracellular DMSP content for I. galbana and D. tertiolecta (Table 2), suggesting that variations beween the 2 approaches may in part be related to taxonomy.

\section{Mechanical sorting of natural populations}

In waters of the eastern Atlantic, mechanical sorting of pre-concentrated cells belonging to 4 phytoplankton groups (Fig. 1) provided sufficient DMSP signal to obtain significant $(p<0.05)$ relationships between cell number sorted and DMSP concentration (Table 3, Fig. 3). For Synechococcus spp. this amounted to between $40 \times 10^{3}$ and $160 \times 10^{3}$ cells sorted and DMSP concentrations of between 350 and 650 pg DMSP, providing estimates of the intracellular DMSP content for Synechococcus spp. of $2.7 \pm 0.9$ and $1.3 \pm 0.3 \mathrm{fg}$ cell $^{-1}$ on 14 and 19 May 2009, respectively (Table 3, Fig. 3). For the picoeukaryotes, numbers of cells sorted ranged between 20 $\times 10^{3}$ and $60 \times 10^{3}$, giving concentrations of 370 to 1500 pg DMSP and corresponding to $16 \pm 4$ and $6 \pm 1 \mathrm{fg} \mathrm{cell}^{-1}$ on 14 and 19 May, respectively (Table 3, Fig. 3). For the cryptophytes, between 2 $\times 10^{3}$ and $10 \times 10^{3}$ cells were sorted and concentrations ranged from 700 to $1600 \mathrm{pg}$ DMSP, resulting in estimates of $116 \pm 20$ and $83 \pm 11 \mathrm{fg} \mathrm{cell}^{-1}$ on the 14 and 19 May, respectively (Table 3, Fig. 3). From $5 \times 10^{3}$ to $25 \times$ $10^{3}$ nanophytoplankton cells were sufficient to provide concentrations of between 4200 and 42000 pg DMSP, giving estimates of $1600 \pm 80$ and $920 \pm 90 \mathrm{fg} \mathrm{cell}^{-1}$ on 14 and 19 May, respectively (Table 3, Fig. 3).

The positive intercept of the linear regression in each case (Table 3, Fig. 3) is attributable to the consistent retention of liquid in the GF/F filters onto which cells were sorted. This liquid consisted primarily of the $0.22 \mu \mathrm{m}$ filtered seawater used as sheath fluid, and

Table 2. Intracellular DMSP content in 3 phytoplankton laboratory cultures: Emiliania huxleyi CCAP 920/3, Isochrysis galbana CCAP 927/1 and Dunaliella tertiolecta CCAP 19/6B. Results $( \pm$ SD) describe the least squares, linear regression analyses $(y=a x+b)$ between number of cells $(x)$ sorted or filtered and DMSP concentration ( $y$ ) (Fig. 2). The coefficient of the slope $a$ provides an estimate of intracellular DMSP content. Values of $b$ are addressed in the section 'Mechanical sorting of laboratory cultures'. $\mathrm{p}$ is the significance of the $F$-ratio of the analysis of variance of the regression

\begin{tabular}{|lcccc|}
\hline $\begin{array}{l}\text { Phytoplankton } \\
\text { group }\end{array}$ & $\begin{array}{c}a \\
(\mathrm{pg} \text { DMSP cell }\end{array}$ & $\begin{array}{c}b \\
\text { ) }\end{array}$ & $\mathrm{r}^{2}$ & $\mathrm{p}$ \\
(pg DMSP) & & & \\
\hline Sorted samples & & & & \\
Emiliania huxleyi & $0.96 \pm 0.02$ & $279 \pm 111$ & 0.99 & $<0.0001$ \\
Isochrysis galbana & $0.41 \pm 0.03$ & $242 \pm 228$ & 0.98 & 0.0002 \\
$\begin{array}{l}\text { Dunaliella tertiolecta } \\
\text { Filtered samples }\end{array}$ & $0.04 \pm 0.01$ & $-78 \pm 97$ & 0.43 & 0.05 \\
Emiliania huxleyi & $1.26 \pm 0.03$ & $1237 \pm 246$ & 1.00 & $<0.0001$ \\
Isochrysis galbana & $0.23 \pm 0.07$ & $1176 \pm 457$ & 0.86 & 0.03 \\
Dunaliella tertiolecta & $0.03 \pm 0.03$ & $68 \pm 225$ & 0.35 & 0.49 \\
\hline
\end{tabular}

Table 3. Mechanical sorting of phytoplankton from the eastern Atlantic. Results $( \pm \mathrm{SD})$ describe the least squares, linear regression analyses $(y=a x+$ $b$ ) between number of cells sorted $(x)$ and DMSP concentration ( $y$ ) (Fig. 3). The coefficient of the slope a provides an estimate of the intracellular DMSP content. Explanation of the values of $b$ is addressed in the section 'Mechanical sorting of natural populations'. $p$ is the significance of the $F$-ratio of the analysis of variance of the regression

\begin{tabular}{|lcccc|}
\hline $\begin{array}{l}\text { Phytoplankton } \\
\text { group }\end{array}$ & $\begin{array}{c}a \\
\left(\mathrm{pg} \mathrm{DMSP} \mathrm{cell}{ }^{-1}\right)\end{array}$ & $\begin{array}{c}b \\
(\mathrm{pg} \text { DMSP })\end{array}$ & $\mathrm{r}^{2}$ & $\mathrm{p}$ \\
\hline $\mathbf{1 4}$ May 2009 & & & & \\
Nanoeukaryotes & $1.60 \pm 0.08$ & $1310 \pm 1290$ & 0.99 & 0.0003 \\
Cryptophytes & $0.116 \pm 0.020$ & $583 \pm 133$ & 0.92 & 0.01 \\
Picoeukaryotes & $0.016 \pm 0.004$ & $593 \pm 152$ & 0.99 & 0.003 \\
Synechococcus spp. & $0.0027 \pm 0.0009$ & $272 \pm 96$ & 0.75 & 0.05 \\
19 May 2009 & & & & \\
Nanoeukaryotes & $0.92 \pm 0.09$ & $869 \pm 1460$ & 0.97 & 0.002 \\
Cryptophytes & $0.083 \pm 0.011$ & $516 \pm 74$ & 0.95 & 0.005 \\
Picoeukaryotes & $0.006 \pm 0.001$ & $272 \pm 39$ & 0.93 & 0.008 \\
Synechococcus spp. & $0.0013 \pm 0.0003$ & $359 \pm 96$ & 0.93 & 0.04 \\
\hline
\end{tabular}



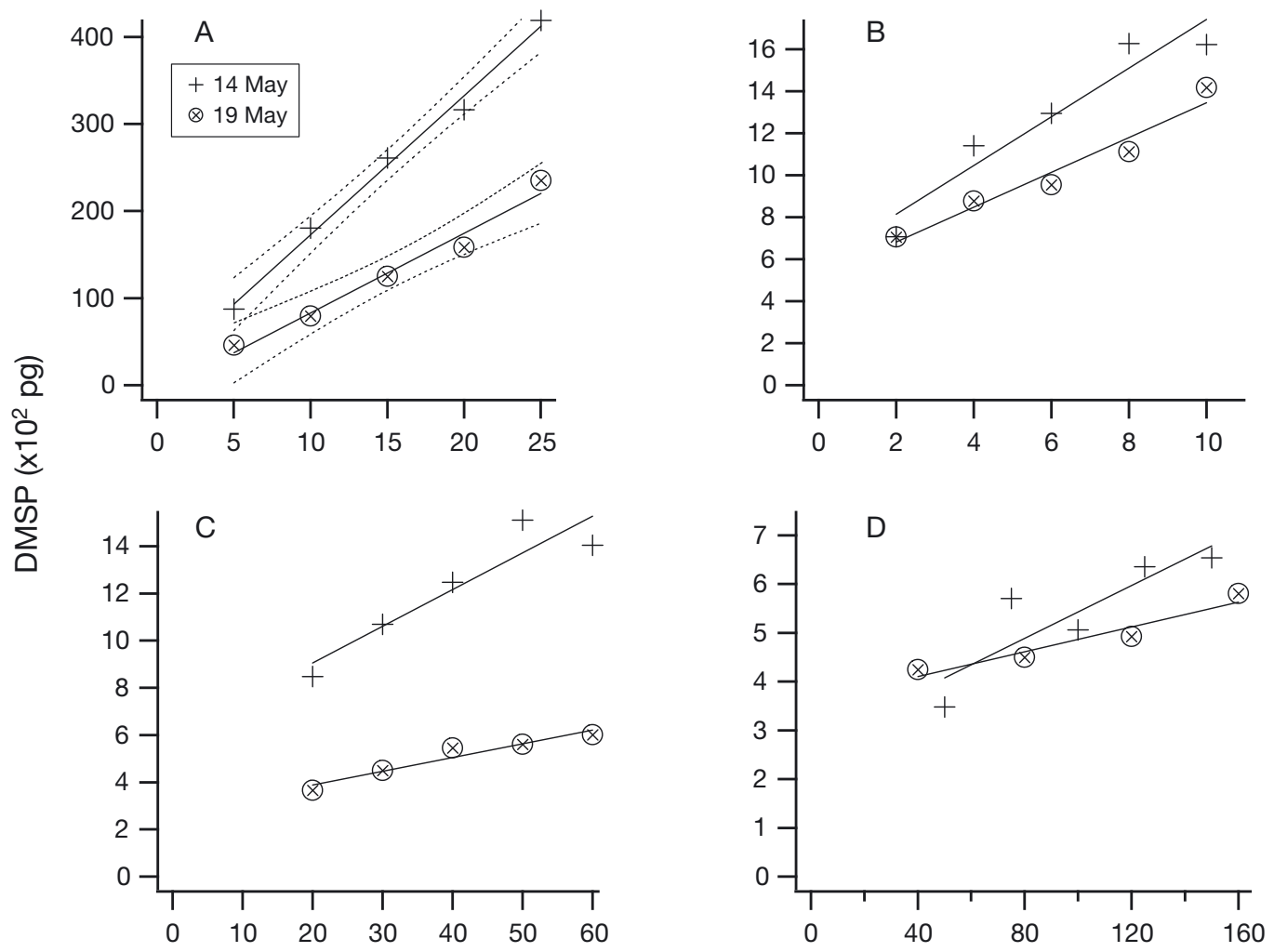

Cell number $\left(\mathrm{x} 10^{3}\right)$

Fig. 3. Intracellular DMSP content in specific microbial groups separated using a mechanical sorting flow cytometer in samples collected in the eastern Atlantic on 2 dates (Table 1): (A) nanoeukaryote phytoplankton; (B) cryptophytes; (C) picoeukaryote phytoplankton; and (D) Synechococcus spp. The parameters and gates used to distinguish and sort each population are shown in Fig. 1. Details of the least squares, linear regression analysis of number of cells sampled versus DMSP concentration are given in

Table 3. The $95 \%$ confidence limits for each regression are shown in (A), but for clarity are omitted in the other plots

which contained $\mathrm{DMSP}_{\mathrm{d}}$ at a concentration of $4.3 \mathrm{nM}$ on 14 May and $3.3 \mathrm{nM}$ on 19 May. Separate tests indicated that the $25 \mathrm{~mm} \mathrm{GF/F}$ filters retained $0.249 \pm$ $0.014 \mathrm{~g}$ of liquid under the experimental conditions and contributed a possible $145 \pm 8$ and $111 \pm 6 \mathrm{pg}$ $\mathrm{DMSP}_{\mathrm{d}}$ to each analysed sample on 14 and 19 May, respectively. These values are within the $95 \%$ confidence intervals of the intercept value for all 4 phytoplankton groups on 14 May but in general are 100 to $200 \mathrm{pg}$ lower than the values for 19 May. Why this is the case is unclear, but suggests that on 19 May the fraction of sample DMSP comprising sheath fluid was underestimated by our calculations of volume retained by the filters.

\section{Droplet sorting of natural populations}

High-speed droplet sorting of pre-concentrated, specific groups of phytoplankton (Fig. 1) from the western English Channel also provided significant relationships $(\mathrm{p}<0.05)$ between numbers of cells sorted and DMSP concentration (Table 4, Fig. 4). In order to deter- mine an intracellular DMSP content, the concentrations of DMSP measured for each sorted sample were adjusted to account for the incorporation of $\mathrm{DMSP}_{\mathrm{d}}$ containing sheath fluid in the receiving vial. Droplet volume containing each sorted cell was $3.57 \pm 0.01 \mathrm{nl}$, determined gravimetrically at a drop-drive frequency of $29 \times 10^{3} \mathrm{~Hz}$ and assumed to consist primarily of sheath fluid, with a total volume added to each vial proportional to the number of cells sorted. The filtered water used as sheath fluid contained 3.1 and $3.4 \mathrm{nmol}$ $\mathrm{l}^{-1} \mathrm{DMSP}_{\mathrm{d}}$ for samples sorted on 6 June 2007 and 27 August 2008, respectively. The relative concentrations of sheath fluid and cellular DMSP in each sample varied in relation to the cell type; for example, sheath fluid from 27 August 2008 contributed 19\% of total DMSP in the vials containing Synechococcus spp. and $<1 \%$ in the large nanoeukaryote samples.

Intracellular DMSP content varied from $6.2 \pm 0.7 \mathrm{fg}$ DMSP cell ${ }^{-1}$ in Synechococcus spp. to as high as $1260 \pm$ $40 \mathrm{fg} \mathrm{cell}^{-1}$ in the larger nanoeukaryote fraction from 6 June 2007 (Table 4, Fig. 4). The flow cytometrically defined nanoeukaryote phytoplankton population covered relatively large variations in side scatter and fluo- 
Table 4. Droplet sorting of specific groups of phytoplankton from the western English Channel. Results $( \pm \mathrm{SD})$ describe the least squares, linear regression analyses $(y=a x+b)$ between number of cells sorted $(x)$ and DMSP concentration $(y)$. Plots for the sample on 6 June 2007 are shown in Fig. 4. The coefficient of the slope $a$ is an estimate of the intracellular DMSP content. Explanation of the values of $b$ is addressed in the section 'Droplet sorting of natural populations'. p is the significance of the F-ratio of the analysis of variance of the regression

\begin{tabular}{|lcccc|}
\hline $\begin{array}{l}\text { Phytoplankton } \\
\text { group }\end{array}$ & $\begin{array}{c}a \\
\text { (pg DMSP cell }\end{array}{ }^{-1}$ ) & $\begin{array}{c}b \\
\text { (pg DMSP) }\end{array}$ & & $\mathrm{r}$ \\
\hline 6 June 2007 & & & & \\
Synechococcus spp. & $0.0062 \pm 0.0007$ & $79 \pm 79$ & 0.96 & 0.006 \\
Picoeukaryotes & $0.030 \pm 0.002$ & $225 \pm 94$ & 0.98 & 0.0002 \\
Nanoeukaryotes & $0.50 \pm 0.02$ & $-159 \pm 403$ & 0.99 & $<0.0001$ \\
Large nanoeukaryotes & $1.26 \pm 0.04$ & $185 \pm 131$ & 1.00 & 0.0008 \\
27 August 2008 & & & & \\
Synechococcus spp. & $0.0094 \pm 0.0003$ & $77 \pm 32$ & 1.00 & 0.001 \\
Picoeukaryotes & $0.012 \pm 0.002$ & $259 \pm 106$ & 0.97 & 0.02 \\
Nanoeukaryotes & $0.73 \pm 0.01$ & $-192 \pm 226$ & 1.00 & 0.0003 \\
Small nanoeukaryotes & $0.22 \pm 0.06$ & $-246 \pm 978$ & 0.82 & 0.04 \\
Large nanoeukaryotes & $1.82 \pm 0.09$ & $87 \pm 288$ & 0.99 & 0.003 \\
\hline
\end{tabular}

sample is shown in Table 5. Nanoeukaryotes dominated the contribution of the defined groups, contributing between 31 and $45 \%$ of the total DMSP. Cells sorted from the larger sort gate within the nanoeukaryote population (Fig. 1A) dominated the total DMSP of the flow cytometrically defined populations from 27 August 2008, although this was not the case in samples from 6 June 2007. Combining larger and smaller fractions of the nanoeukaryote populations results in a higher estimate of the total nanoeukaryote DMSP than when the complete population from 27 August 2008 was sorted (Table 5). This may reflect the fact that the sort gates defined for the small and large fractions do not cover the full nanoeukaryote population (Fig. 1A). Picoeukaryote and cryptophyte populations contributed relative minor proportions to the total DMSP in these particular waters, whilst Synechococcus rescence characteristics. In samples from 27 August 2008, smaller and larger sub-populations within the full nanoeukaryote population were defined and sorted (Fig. 1A). They varied in intracellular DMSP content from $220 \pm 60$ to $1820 \pm 90 \mathrm{fg}^{\mathrm{DMSP}} \mathrm{cell}^{-1}$, in comparison to the value of $730 \pm 10 \mathrm{fg}^{\mathrm{DMSP}} \mathrm{cell}^{-1}$ when the total population was defined as the sort gate (Table 4).

\section{Contribution to total DMSP concentrations}

The contribution of each phytoplankton group to the measured total DMSP concentration in each water

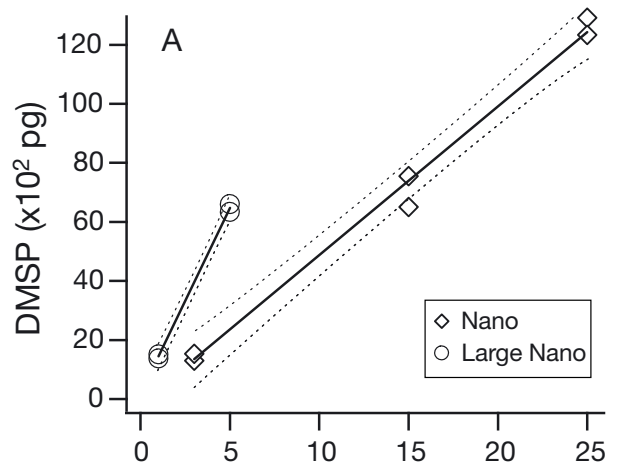

spp. contributed between 2 and $21 \%$ of the total DMSP, with the highest value observed in midsummer in the western English Channel. The defined phytoplankton groups accounted for between 40 and $57 \%$ of the total measured DMSP in the 4 water samples.

\section{DISCUSSION}

The present study illustrates that by using a FACS$\mathrm{GC}$ approach it is possible to obtain significant $(\mathrm{p}<$ 0.05) estimates of the intracellular DMSP content of cultivated strains of microalgae and of phytoplankton

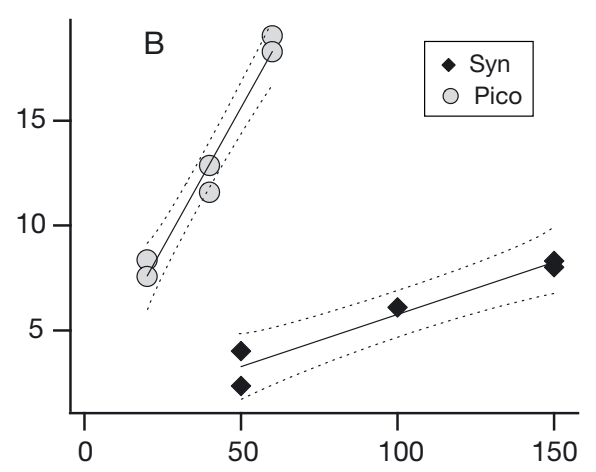

Cell number $\left(x 10^{3}\right)$

Fig. 4. Intracellular DMSP content in specific phytoplankton groups separated using a droplet sorting flow cytometer in a sample collected in the western English Channel on 6 June 2007 (Table 1): (A) nanophytoplankton (Nano: full nanoeukaryotic phytoplankton; Large Nano: nanoeukaryotic phytoplankton sub-population with higher fluorescence and side scatter) and (B) picophytoplankton (Syn: Synechococcus spp.; Pico: picoeukaryotic phytoplankton). The parameters used to distinguish each population are shown in Fig. 1. Details of the least squares, linear regression analysis of number of cells sampled versus DMSP concentration are given in Table 4 . Dotted lines are the $95 \%$ confidence limits 
Table 5. Phytoplankton group-specific percent contributions to the total DMSP concentrations measured in each water sample (Table 1), calculated from the intracellular DMSP content and abundance for each group. Large and small nanoeukaryote groups are sub-groups of the main nanoeukaryote populations (Fig. 1). Errors shown are SD based on estimates of intracellular DMSP content and do not incorporate uncertainty in the cell counts. Coefficients of variation for cell counts of specific phytoplankton groups from triplicate subsamples from each water bottle were $<2 \%$. Values in square brackets are not included in the calculation of the total contribution as they are a component of the full nanoeukaryote population

\begin{tabular}{|lcccr|}
\hline $\begin{array}{l}\text { Phytoplankton } \\
\text { group }\end{array}$ & $\begin{array}{c}\text { 14 May } \\
2009\end{array}$ & $\begin{array}{c}\text { 19 May } \\
2009\end{array}$ & $\begin{array}{c}\text { 6 June } \\
2007\end{array}$ & \multicolumn{1}{c|}{$\begin{array}{c}\text { 27 August } \\
2008\end{array}$} \\
\hline $\begin{array}{l}\text { Synechococcus spp. } \\
\text { Picoeukaryotes }\end{array}$ & $8 \pm 2.7$ & $4 \pm 0.9$ & $21 \pm 2.4$ & $2 \pm 0.1$ \\
$\begin{array}{l}\text { Nanoeukaryotes } \\
\text { Small nanoeukaryotes }\end{array}$ & $36 \pm 2.5$ & $33 \pm 3.2$ & $31 \pm 1.2$ & $\begin{array}{r}45 \pm 0.8 \\
{[7 \pm 1.8]}\end{array}$ \\
$\begin{array}{l}\text { Large nanoeukaryotes } \\
\text { Cryptophytes }\end{array}$ & $2 \pm 0.3$ & $2 \pm 0.2$ & {$[8 \pm 0.3]$} & {$[49 \pm 2.4]$} \\
Total contribution (\%) & 49 & 40 & 57 & 52 \\
\hline
\end{tabular}

groups that are routinely encountered in natural waters. As will be discussed, the approach has several advantages over size fractionation or correlative methods to partition natural DMSP standing stocks amongst phytoplankton functional types (PFTs). It is a potentially powerful tool that may have particular benefits in laboratory- and field-based studies of the physiological role of DMSP, potentially improving our capability to predict DMS production in mechanistic models.

Conventional approaches to determine intracellular DMSP content of cultivated phytoplankton have used filtration either to collect the particulate fraction of DMSP or to determine the dissolved component of the total DMSP pool, from which a particulate fraction can be estimated by difference (Keller et al. 1989, Archer et al. 2010). The intention of the filtration-based estimates of the present study was to provide a bench mark against which to compare the FACS-GC approach. Whilst values for Isochrysis galbana CCAP 927/1 and Dunaliella tertiolecta CCAP 19/6B were not significantly different (Table 2), the significantly higher filtration-based estimates of intracellular DMSP content in Emiliania huxleyi CCAP 920/3 make it difficult to draw conclusions about the accuracy of the FACS-GC approach. It does, however, raise some uncertainty in the routinely used filtration approach, as applied in the present study. In particular, the high intercept values from the relationship between number of filtered cells and DMSP concentration in the $E$. huxleyi and I. galbana cultures (Fig. 2B) suggest that DMSP not contained in the enumerated phytoplankton cells was retained by the GF/F filters. Possible sources include compromised phytoplankton cells that lacked sufficient autofluorescence to be included in the flow cytometric counts, bacterial cells in the non-axenic cultures, cell debris or possibly $\mathrm{DMSP}_{\mathrm{d}}$ retained in the filter volume despite the rinsing of filters with sterile media. This may account for the higher filtration-based estimates of intracellular DMSP content in E. huxleyi (Table 2). In the case of the laboratory cultures, the $\geq 95 \%$ recovery of cells following mechanical sorting (see 'Materials and methods') and quantification of DMS and DMSP in the entire sorted volume, including the sheath fluid and minor component of the original culture media in the sorted sample stream (see 'Results'), means that any loss of DMSP from the cells, either as DMSP or DMS, is likely to have been included in the estimates of intracellular DMSP content. It is less straightforward to verify the integrity of cells collected on GF/F filters, but variations in response to mechanical stress have been shown to be species specific (Wolfe et al. 2002), possibly explaining the taxonomic differences observed when comparing mechanically sorted and filtered samples.

The values of intracellular DMSP content in the laboratory cultures generated from both cell sorting and filtration approaches (Table 2) are consistent with previous studies, accepting that intracellular DMSP content may alter with growth environment and between culture strains. For instance, the $960 \pm 20 \mathrm{fg}$ DMSP cell $^{-1}$ value measured in Emiliania huxleyi CCAP 920/3 falls within the range of 1860 to $730 \mathrm{fg}$ DMSP cell $^{-1}$ measured in filtered samples from cultures of $E$. huxleyi B92/11 acclimated to low or high light, respectively (Archer et al. 2010). Similarly, the value obtained by using the FACS-GC approach falls within the 5-fold variation of 470 to $2440 \mathrm{fg}$ DMSP cell ${ }^{-1}$ found in 6 strains of E. huxleyi (Steinke et al. 1998). Previous reports of DMSP content in Isochrysis galbana range from a very low value of $60 \mathrm{fg}$ DMSP cell ${ }^{-1}$ for the same strain used in the present study (Hatton \& Wilson 2007), to a more comparable value of $500 \mathrm{fg}$ DMSP cell $^{-1}$ in I. galbana ISO (Keller et al. 1989). Although Dunaliella tertiolecta is sometimes considered not to produce DMSP, the FACS-GC approach was sufficiently sensitive to confirm that strain 19/6B has low intracellular DMSP content $\left(40 \pm 10 \mathrm{fg}\right.$ DMSP cell $\left.{ }^{-1}\right)$ (Table 2), as also observed in strain D. tertiolecta (DUN) (Matrai \& Keller 1994). The major benefit that FACS-GC based determination of intracellular DMSP content provides over other approaches is the potential to physically separate different cell types. This may prove useful in studies on the influence of DMSP and derivatives on the interactions between phytoplankton 
prey and protozoan grazers, amongst phytoplankton species and between phytoplankton and bacteria. It may be possible to combine flow cytometric determination of the physiological status of specific cells (Jochem 2000) with the determination of their intracellular DMSP content.

The high proportion of total DMSP accounted for by the flow cytometrically defined phytoplankton populations substantiates the potential value of this approach for model parameterisation or validation and for deciphering the environmental factors that control the diversity of DMSP production. The 40 to $57 \%$ of total DMSP accounted for by the sorted groups in the present study (Table 5) compares favourably with the average $( \pm \mathrm{SD})$ of $65 \pm 16 \%$ of total particulate DMSP found in the $<10 \mu \mathrm{m}$ size fraction in 200 samples compiled from contrasting regions of the oceans (Belviso et al. 2001). It also demonstrates that the DMSP in this size fraction is likely to be primarily of phytoplankton origin. Moreover, the present study confirms the importance of nanoeukaryotic phytoplankton to DMSP standing stocks in the surface ocean (Table 5). The intracellular DMSP content of the natural nanoeukaryote populations was relatively high, being similar to values measured in a variety of cultivated prymnesiophyte taxa of similar size ( 0.79 to $1.83 \mathrm{pg}$ DMSP cell ${ }^{-1}$ ) that are considered to be high DMSP producers (Keller \& Korjeff-Bellows 1996). The values are similar to those measured in the 2 strains of Emiliania huxleyi and Isochrysis galbana during the present study (Table 2), both of which would fall within the nanoeukaryote gates set for the natural seawater samples (Fig. 1). The separation of the nanoeukaryote group into large and small fractions from 27 August 2008 (Fig. 1) illustrated that cells within the sorting gate group varied 8-fold in intracellular DMSP content (Table 4), possibly reflecting differences in cell volume rather than intracellular DMSP concentration. For instance, an equivalent 8 -fold difference in volume exists between cells of 2.5 and $5 \mu \mathrm{m}$ diameter, reasonable estimates of the average size of cells in the 2 sub-fractions. Attempts to define cell size by flow cytometry are complicated by the lack of a straightforward relationship between cell size and light scatter (Vives-Rego et al. 2000). An indication of phytoplankton size distribution has been determined by combining filter fractionation with flow cytometric analysis (Tarran et al. 2001) and this approach could be extended to the determination of intracellular DMSP amongst the cells of each size class.

The sometimes high proportion of the total DMSP contained in picophytoplankton has been attributed primarily to photosynthetic picoeukaryotes, but the FACS-GC based approach indicates that this may not be the case. Filter fractionation of samples from the Mediterranean and sub-tropical Atlantic indicated that picoplankton $(0.7$ to $2 \mu \mathrm{m})$ account for 2 to $25 \%$ of the total DMSP pool (Corn et al. 1996). Measurements of intracellular DMSP content of a variety of prokaryote and eukaryote strains grown in culture in combination with measurements of natural cell abundance suggested that eukaryotes made up the overwhelming fraction of this picoplanktonic DMSP (Corn et al. 1996). However, the present study illustrates that cyanobacteria, in particular Synechococcus spp., may equal or exceed the contribution by picoeukaryotes (Table 5).

Direct estimates of intracellular DMSP content in picoeukaryotes in the eastern Atlantic and western English Channel ranged from 6 to $30 \mathrm{fg}$ DMSP cell ${ }^{-1}$ (Tables $3 \& 4$ ) and are similar to those measured in laboratory cultures of picoplanktonic prasinophytes and chlorophytes (Corn et al. 1996). The prasinophyte Micromonas pusilla is generally the dominant photosynthetic picoeukaryote in the western English Channel (Not et al. 2004), and is likely to have had a substantial influence on the values of DMSP in the picoeukaryote populations in samples from 6 June 2007 and 27 August 2008 (Table 4). M. pusilla is widespread in temperate coastal and oceanic waters and the FACS-GC based values of intracellular DMSP content may be representative of the picoeukaryote populations in these waters. Conversely, flow cytometric sorting in combination with the construction of $18 \mathrm{~S}$ rRNA gene clone libraries revealed a spatially and vertically highly variable picoeukaryote population dominated by uncultivated lineages in the oligotrophic southeast Pacific (Shi et al. 2009). The intracellular DMSP content of picoeukaryotes in oligotrophic waters may be more variable as a consequence of the greater diversity of dominant species. FACS-GC based determination of intracellular DMSP content in combination with taxonomic characterisation through fluorescence in situ hybridisation or 18S rRNA gene clone libraries may prove powerful approaches to determine the principal producers of DMSP amongst picoeukaryote and nanoeukaryote phytoplankton.

Mechanical and droplet sorting approaches provided robust $(p<0.05)$ estimates of DMSP content of the natural Synechococcus spp. of 6 to $27 \mathrm{fg}$ DMSP cell $^{-1}$ (Tables $3 \& 4$ ). These values are $>3$ orders of magnitude higher than those measured in 3 strains maintained in culture (Corn et al. 1996). This discrepancy is unlikely to be due to the different analytical approaches between the studies. Although not specified, relatively high numbers of cells are likely to have been present in samples of cultured Synechococcus spp. and the analytical system used for measuring DMSP concentrations was of similar sensitivity to that 
used in the present study (Corn et al. 1996). It is possible that inter-strain differences in Synechococcus spp. intracellular DMSP content are even greater than the 2 -fold variation observed between the 3 strains examined by Corn et al. (1996). Alternatively, cultured strains may lose the requirement or ability to synthesise or accumulate high intracellular DMSP concentrations. Assuming a similar cell volume to the cultured strains $\left(0.5 \mu^{3}\right)$ suggests an intracellular DMSP concentration of 20 to $140 \mathrm{mmol} \mathrm{l}^{-1}$ for the natural Synechococcus spp. from the eastern Atlantic and western English Channel. These concentrations are not unreasonable, being comparable to many DMSP-producing, eukaryotic phytoplankton in culture (Matrai \& Keller 1994). Natural populations of Synechococcus spp. have been shown to assimilate sulphur from DMSP into high molecular weight biomass (Malmstrom et al. 2005). The intracellular DMSP content observed in FACS samples suggests that Synechococcus spp. may also sequester DMSP. FACS of unpreserved samples following ${ }^{35} \mathrm{~S}$-DMSP tracer additions, in combination with estimates of intracellular DMSP content, may help to elucidate whether Synechococcus spp., and other groups, synthesise or accumulate intracellular pools of DMSP.

Although highly informative in their present form, both mechanical- and droplet-FACS-GC approaches to determine intracellular DMSP content could be improved in several respects. Both approaches would benefit from further investigation into optimisation of the sheath fluid composition. In part to increase sensitivity when sorting cells containing relatively low DMSP, the seawater filtrate containing $\mathrm{DMSP}_{d}$ was used as sheath fluid in each application. Although not a complication when the mechanically sorted samples were collected on filters, a correction for the $\mathrm{DMSP}_{\mathrm{d}}$ component was required when droplet sorting was carried out (see 'Results'). Use of artificial seawater as sheath fluid may be a superior approach, obviating the need to apply any correction, whilst better maintaining cell integrity than proprietary sheath fluids or Milli-Q water. Increased sensitivity could equally effectively be achieved by doping of sorted and fixed samples with known precise quantities of DMSP. Investigation into the extent to which optical and hydrodynamic stresses involved in each cell sorting approach (Olson et al. 1993) affect intracellular DMSP content may be required, particularly for species or strains possessing high DMSP-cleavage capacity. Similarly, although not achieved in the present study, the affect of pre-concentration on the particulate DMSP pool should be monitored and approaches that minimise cell disruption and loss of DMSP should be investigated. For instance, it may be possible to optimise sample pre-concentration to the particular planktonic groups under investi- gation, taking into account natural cell abundance and instrument sorting rates. Decreasing the time required for preconcentration and controlling the environment during the process would certainly benefit attempts to examine links between physiological state and DMSP cell content.

Of greater value to modellers would be simultaneous information on the relative contribution that intracellular DMSP makes to the content of FACS phytoplankton groups in terms of modelled currency; either carbon, nitrogen or possibly sulphur. There are an increasing number of biochemical techniques that potentially have sufficient sensitivity to determine the elemental composition of the relatively low amount of biomass produced in FACS samples. These include X-ray microanalysis (Heldal et al. 1985), modified isotope ratio mass spectrometry (IRMS) (Eek et al. 2007) and secondary ion mass spectrometry (SIMS) (Orphan \& House 2009). The latter 2 approaches potentially provide estimates of stable isotopic composition of small sample sizes, opening up the potential to combine FACS-GC based estimates of intracellular DMSP content in specific groups with measures of their metabolic activity, including possibly in vitro DMSP synthesis (Stefels et al. 2009). One advantage of the mechanicalFACS mechanism is the capability to use radioisotope tracers to determine metabolic activity, including DMSP uptake, in specific components of microbial populations (Zubkov et al. 2001, Vila-Costa et al. 2006) without the problems associated with production of radioactive aerosols that droplet-FACS mechanisms potentially produce.

In recommending which PFTs should be included in mechanistic DMS models, Stefels et al. (2007) defined 6 groups on the basis of cell size, DMSP content and DMSP-lyase activity. Encouragingly, the FACS-GC approach presented here potentially provides information on the intracellular DMSP content of 4 of these PFTs. If present in sufficient numbers, it may also be possible to determine the intracellular DMSP content of the smaller components ( 20 to $60 \mu \mathrm{m}$ ) of the remaining 2 larger PFTs comprising dinoflagellates and diatoms of 20 to $200 \mu \mathrm{m}$. Additionally, the FACS-GC approach may be of value in validating phytoplankton types that emerge from any future attempts to apply stochastic modelling strategies (Follows et al. 2007) to study the relations between ecosystem structure, DMS biogeochemistry and climate change. Further studies are required to expand our understanding of how the interplay between taxonomic composition and environmental forcing determines the intracellular DMSP content of PFTs and, ultimately, DMS production. This will require optimisation of the FACS-GC approach and its application in interdisciplinary studies of DMS biogeochemistry. 
Acknowledgements. We are grateful to 3 anonymous reviewers for improvements to an earlier version of this manuscript. The work was partially funded by the Natural Environment Research Council (NERC) as part of the Surface Ocean Lower Atmosphere Studies (SOLAS) programme (ICON: NE/ C517176/1) and contributes to the Plymouth Marine Laboratory component of the NERC Oceans 2025 programme.

\section{LITERATURE CITED}

Archer SD, Widdicombe CE, Tarran GA, Rees AP, Burkill PH (2001) Production and turnover of particulate dimethylsulphoniopropionate during a coccolithophore bloom in the northern North Sea. Aquat Microb Ecol 24:225-241

> Archer SD, Gilbert FJ, Allen JI, Blackford J, Nightingale PD (2004) Modelling of the seasonal patterns of dimethylsulphide production and fate during 1989 at a site in the North Sea. Can J Fish Aquat Sci 61:765-787

- Archer SD, Ragni M, Webster R, Airs RL, Geider RJ (2010) Dimethyl sulfoniopropionate and dimethyl sulfide production in response to photoinhibition in Emiliania huxleyi. Limnol Oceanogr 55:1579-1589

Belviso S, Buatmenard P, Putaud JP, Nguyen BC, Claustre H, Neveux J (1993) Size distribution of dimethylsulfoniopropionate (DMSP) in areas of the tropical northeastern Atlantic Ocean and the Mediterranean Sea. Mar Chem 44: 55-71

Belviso S, Christaki U, Vidussi F, Marty JC, Vila M, Delgado M (2000) Diel variations of the DMSP-to-chlorophyll a ratio in northwestern Mediterranean surface waters. J Mar Syst 25:119-128

Belviso S, Claustre H, Marty JC (2001) Evaluation of the utility of chemotaxonomic pigments as a surrogate for particulate DMSP. Limnol Oceanogr 46:989-995

Challenger F, Simpson M (1948) Studies on biological methylation. Part XII. A precursor of dimethylsulfide evolved by Polysiphonia fastigiata. Dimethyl-2-carboxyethylsulfonium hydroxide and its salts. J Chem Soc 43:1591-1597

Charlson RJ, Lovelock JE, Andreae MO, Warren SG (1987) Oceanic phytoplankton, atmospheric sulfur, cloud albedo and climate. Nature 326:655-661

Corn M, Belviso S, Partensky F, Simon N, Christaki U (1996) Origin and importance of picoplanktonic DMSP. In: Kiene RP, Visscher PT, Keller MD, Kirst GO (eds) Biological and environmental chemistry of DMSP and related sulphonium compounds. Plenum Press, New York, p 191-201

- Eek KM, Sessions AL, Lies DP (2007) Carbon-isotopic analysis of microbial cells sorted by flow cytometry. Geobiology 5:85-95

Follows MJ, Dutkiewicz S, Grant S, Chisholm SW (2007) Emergent biogeography of microbial communities in a model ocean. Science 315:1843-1846

Gage DA, Rhodes D, Nolte KD, Hicks WA, Leustek T, Cooper AJL, Hanson AD (1997) A new route for synthesis of dimethylsulphoniopropionate in marine algae. Nature 387 : 891-894

Guillard RRL, Ryther JH (1962) Studies of marine planktonic diatoms. I. Cyclotella nana Hustedt and Detonula confervacea (cleve) Gran. Can J Microbiol 8:229-239

Hatton AD, Wilson ST (2007) Particulate dimethylsulphoxide and dimethylsulphoniopropionate in phytoplankton cultures and Scottish coastal waters. Aquat Sci 69:330-340

> Heldal M, Norland S, Tumyr O (1985) X-ray microanalytic method for measurement of dry matter and elemental content of individual bacteria. Appl Environ Microbiol 50: 1251-1257
Jean N, Boge G, Jamet JL, Richard S, Jamet D (2005) Annual contribution of different plankton size classes to particulate dimethylsulfoniopropionate in a marine perturbed ecosystem. J Mar Syst 53:235-247

Jochem FJ (2000) Probing the physiological state of phytoplankton at the single-cell level. Sci Mar 64:183-195

Keller MD, Korjeff-Bellows W (1996) Physiological aspects of the production of dimethylsulfoniopropionate (DMSP) in marine phytoplankton. In: Kiene RP, Visscher PT, Keller MD, Kirst GO (eds) Biological and environmental chemistry of DMSP and related sulfonium compounds. Plenum Press, New York, NY, p 131-142

Keller MD, Bellows WK, Guillard RRL (1989) Dimethyl sulfide production in marine phytoplankton. In: Saltzman ES, Cooper WJ (eds) Biogenic sulfur in the environment. American Chemical Society, Washington, DC, p 183-200

Kiene RP, Linn LJ, Bruton JA (2000) New and important roles for DMSP in marine microbial communities. J Sea Res 43: 209-224

Leck C, Bigg EK (2005) Source and evolution of the marine aerosol-a new perspective. Geophys Res Lett 32: L19803 doi:10.1029/2005GL023651

> Malin G, Turner S, Liss P, Holligan P, Harbour D (1993) Dimethylsulphide and dimethylsulphoniopropionate in the Northeast Atlantic during the summer coccolithophore bloom. Deep-Sea Res I 40:1487-1508

> Malmstrom RR, Kiene RP, Vila M, Kirchman DL (2005) Dimethylsulfoniopropionate (DMSP) assimilation by Synechococcus in the Gulf of Mexico and northwest Atlantic Ocean. Limnol Oceanogr 50:1924-1931

Matrai PA, Keller MD (1993) Dimethylsulfide in a large-scale coccolithophore bloom in the Gulf of Maine. Cont Shelf Res 13:831-843

Matrai PA, Keller MD (1994) Total organic sulfur and dimethylsulfoniopropionate in marine phytoplanktonintracellular variations. Mar Biol 119:61-68

Not F, Latasa M, Marie D, Cariou T, Vaulot D, Simon N (2004) A single species, Micromonas pusilla (Prasinophyceae), dominates the eukaryotic picoplankton in the western English Channel. Appl Environ Microbiol 70:4064-4072

Olson RJ, Zettler ER, DuRand MD (1993) Phytoplankton analysis using flow cytometry. In: Kemp PF, Sherr BF, Sherr EB, Cole JJ (eds) Handbook of methods in aquatic microbial ecology. Lewis Publishers, Chelsea, MI, p 175-186

> Orphan VJ, House CH (2009) Geobiological investigations using secondary ion mass spectrometry: microanalysis of extant and paleo-microbial processes. Geobiology 7: 360-372

$>$ Shaw GE (1983) Biocontrolled thermostasis involving the sulfur cycle. Clim Change 5:297-303

Shi XL, Marie D, Jardillier L, Scanlan DJ, Vaulot D (2009) Groups without cultured representatives dominate eukaryotic picophytoplankton in the oligotrophic South East Pacific Ocean. PLoS ONE 4:e7657

> Simó R, Archer SD, Pedrós-Alió C, Gilpin L, Stelfox-Widdicombe CE (2002) Coupled dynamics of dimethylsulfoniopropionate and dimethylsulfide cycling and the microbial food web in surface waters of the North Atlantic. Limnol Oceanogr 47:53-61

Six KD, Maier-Reimer E (2006) What controls the oceanic dimethylsulfide (DMS) cycle? A modeling approach. Glob Biogeochem Cycle 20: GB4011 doi:10.1029/2005 GB002674

Stefels J, Steinke M, Turner S, Malin G, Belviso S (2007) Environmental constraints on the production and removal of the climatically active gas dimethylsulphide (DMS) and 
implications for ecosystem modelling. Biogeochemistry 83:245-275

Stefels J, Dacey JWH, Elzenga JTM (2009) In vivo DMSPbiosynthesis measurements using stable-isotope incorporation and proton-transfer-reaction mass spectrometry (PTR-MS). Limnol Oceanogr Methods 7:595-611

Steinke M, Wolfe GV, Kirst GO (1998) Partial characterisation of dimethylsulfoniopropionate (DMSP) lyase isozymes in 6 strains of Emiliania huxleyi. Mar Ecol Prog Ser 175:215-225

Tarran GA, Zubkov MV, Sleigh MA, Burkill PH, Yallop M (2001) Microbial community structure and standing stocks in the NE Atlantic in June and July of 1996. Deep-Sea Res II 48:963-985

Turner SM, Malin G, Liss PS, Harbour DS, Holligan PM (1988) The seasonal variation of dimethyl sulfide and dimethylsulfoniopropionate concentrations in nearshore waters. Limnol Oceanogr 33:364-375

> Vila-Costa M, Simó R, Harada H, Gasol JM, Slezak D, Kiene RP (2006) Dimethylsulfoniopropionate uptake by marine phytoplankton. Science 314:652-654

Vives-Rego J, Lebaron P, Nebe-von Caron G (2000) Current and future applications of flow cytometry in aquatic microbiology. FEMS Microbiol Rev 24:429-448

Editorial responsibility: Josep Gasol,

Barcelona, Spain
Vogt R, Crutzen PJ, Sander R (1996) A mechanism for halogen release from sea-salt aerosol in the remote marine boundary layer. Nature 383:327-330

> Vogt M, Vallina SM, Buitenhuis ET, Bopp L, Le Qee C (2010) Simulating dimethylsulphide seasonality with the Dynamic Green Ocean Model PlankTOM5. J Geophys Res 115: C06021 doi:10.1029/2009JC005529

von Glasow R, Crutzen PJ (2004) Model study of multiphase DMS oxidation with a focus on halogens. Atmos Chem Phys 4:589-608

> Wolfe GV, Strom SL, Holmes JL, Radzio T, Olson MB (2002) Dimethylsulfoniopropionate cleavage by marine phytoplankton in response to mechanical, chemical, or dark stress. J Phycol 38:948-960

Yentsch CM, Horan PK, Muirhead K, Dortch Q and others (1983) Flow cytometry and cell sorting: a technique for analysis and sorting of aquatic particles. Limnol Oceanogr 28:1275-1280

Zubkov MV, Fuchs BM, Archer SD, Kiene RP, Amann R, Burkill PH (2001) Linking the composition of bacterioplankton to rapid turnover of dissolved dimethylsulphoniopropionate in an algal bloom in the North Sea. Environ Microbiol 3:304-311

Submitted: May 14, 2010; Accepted: October 1, 2010 Proofs received from author(s): November 18, 2010 